\title{
Impact of future Arctic shipping on high-latitude black carbon deposition
}

\author{
J. Browse, ${ }^{1}$ K. S. Carslaw, ${ }^{1}$ A. Schmidt, ${ }^{1}$ and J. J. Corbett ${ }^{2}$ \\ Received 7 June 2013; revised 31 July 2013; accepted 13 August 2013; published 28 August 2013.
}

[1] The retreat of Arctic sea ice has led to renewed calls to exploit Arctic shipping routes. The diversion of ship traffic through the Arctic will shorten shipping routes and possibly reduce global shipping emissions. However, deposition of black carbon (BC) aerosol emitted by additional Arctic ships could cause a reduction in the albedo of snow and ice, accelerating snowmelt and sea ice loss. Here we use recently compiled Arctic shipping emission inventories for 2004 and 2050 together with a global aerosol model to quantify the contribution of future Arctic shipping to high-latitude BC deposition. Our results show that Arctic shipping in 2050 will contribute less than $1 \%$ to the total $\mathrm{BC}$ deposition north of $60^{\circ} \mathrm{N}$ due to the much greater relative contribution of $\mathrm{BC}$ transported from non-shipping sources at lower latitudes. We suggest that regulation of the Arctic shipping industry will be an insufficient control on high-latitude BC deposition. Citation: Browse, J., K. S. Carslaw, A. Schmidt, and J. J. Corbett (2013), Impact of future Arctic shipping on high-latitude black carbon deposition, Geophys. Res. Lett., 40, 4459-4463, doi:10.1002/grl.50876.

\section{Introduction}

[2] The dramatic decline in Arctic sea ice extent over the past few decades has led to growth of the existing industry and renewed interest in trans-Arctic shipping [Corbett et al., 2010]. Expansion of Arctic shipping could reduce net global ship emissions by decreasing traffic through the longer sea routes. However, there is concern that an increase in anthropogenic activity in the Arctic could contribute to regional climate forcing [Ødemark et al., 2012; Dalsøren et al., 2007].

[3] Emissions from Arctic ships are likely to increase the mass of black carbon (BC) deposited on sea ice and snow surfaces. BC deposition has been identified as a particularly efficient forcing mechanism that can increase surface temperatures and accelerate snowmelt [Flanner, 2013].

[4] New aerosol emission inventories for the Arctic region [Corbett et al., 2010] allow the effect of increased ship traffic on Arctic BC deposition to be quantified for the first time. Here we use these inventories together with a global aerosol microphysics model to calculate the increase in $\mathrm{BC}$ deposition attributable to the growth of the Arctic

\footnotetext{
${ }^{1}$ Institute for Climate and Atmospheric Science, University of Leeds, Leeds, UK.

${ }^{2}$ College of Earth, Ocean and Atmosphere, University of Delaware, Newark, Delaware, USA.

Corresponding author: J. Browse, Institute for Climate and Atmospheric Science, University of Leeds, Woodhouse Ln, Leeds LS2 9JT, UK. (earjbr@leeds.ac.uk)

(C)2013. American Geophysical Union. All Rights Reserved. 0094-8276/13/10.1002/grl.50876
}

shipping industry between 2004 and 2050 under different economic and political scenarios.

\section{Model Description}

[5] We use a global model of aerosol processes (GLOMAP) [Mann et al., 2010], coupled to the chemical transport model TOMCAT [Breider et al., 2010]. The model was run at a resolution of $2.8^{\circ} \times 2.8^{\circ}$ with 31 vertical levels extending from the surface to $10 \mathrm{hPa}$. GLOMAP uses a twomoment size-resolving scheme to calculate particle mass and number distribution in four variable size lognormal modes: nucleation (diameter $\sim 3-15 \mathrm{~nm})$, Aitken, $(\sim 10-50 \mathrm{~nm}$ ), accumulation $(\sim 50-200 \mathrm{~nm})$, and coarse $(\sim 1000 \mathrm{~nm})$.

[6] Anthropogenic BC is emitted into a lognormal mode with a standard deviation of 1.59 and geometric mean diameter of $60 \mathrm{~nm}$ [Stier et al., 2005]. At emission, BC particles are assumed to be water insoluble but can become active in cloud drop formation as soluble material accumulates on them [Mann et al., 2010]. After BC particles become cloud active, they are more efficiently wet scavenged, which accounts for $80 \%$ of modeled BC deposition [Mann et al., 2010].

[7] Recent improvements to the wet deposition scheme in GLOMAP mean that the model is now able to reproduce the observed seasonality and magnitude of atmospheric $\mathrm{BC}$ mass concentrations at Arctic ground sites well [Browse et al., 2012]. As GLOMAP does not diagnose snow depth, direct comparison with deposition measurements is not possible as the deposition is typically reported as the $\mathrm{BC}$ to water ratio within a snow layer [Doherty et al., 2010]. However, comparison with a similar study [Skeie et al., 2011] capable of simulating snow burden is possible.

[8] The total deposited mass of $\mathrm{BC}$ north of $65^{\circ} \mathrm{N}$ in GLOMAP at the end of April $(22 \mathrm{Gg})$ is approximately double that calculated for 2004 in Skeie et al. [2011]. Anthropogenic and wildfire $\mathrm{BC}$ emissions north of $40^{\circ} \mathrm{N}$ in the two studies are similar ( 1 and $0.2 \mathrm{Tg}$ ) as is the $\mathrm{BC}$ deposition from wildfires $(0.7$ and $1 \mathrm{Gg})$. Thus, the greater $\mathrm{BC}$ mass deposited in GLOMAP is likely attributable to more efficient transport from lower latitudes, a hypothesis supported by the significant underestimation (factor of 10) in Skeie et al. [2011] of springtime BC aerosol concentrations (which are sourced predominantly from lower latitudes) at the ground stations Barrow $\left(71^{\circ} \mathrm{N}, 156^{\circ} \mathrm{W}\right)$ and Zeppelin Mountain $\left(78^{\circ} \mathrm{N}, 12^{\circ} \mathrm{E}\right)$, which are reproduced well in GLOMAP [Browse et al., 2012].

\section{Present-Day Emission Inventories}

[9] This study makes use of the detailed Arctic shipping emission inventories of Corbett et al. [2010]. Emission rates 
of $\mathrm{SO}_{x}\left(\mathrm{SO}_{2}\right.$ and $\left.\mathrm{SO}_{4}\right)$ and particulate matter $(\mathrm{PM})$ were estimated from the duration, route, engine power, and load of each ship journey using the $\mathrm{SO}_{x}$ and $\mathrm{PM}$ emission factors derived from the second International Maritime Organization greenhouse gas study [Buhaug et al., 2009]. The BC and organic carbon (OC) component emission rates were derived from the PM speciation fractions of Lack et al. [2008] and Lack et al. [2009]. The Corbett et al. [2010] inventory does not include fishing vessels, so these are omitted in the present study. The impact of this omission is discussed below.

[10] The seasonally resolved Corbett et al. [2010] inventories (hereafter referred to as $\mathrm{C} 10$ ) were interpolated from a $5 \times 5 \mathrm{~km}$ grid to a spatially inhomogeneous $1^{\circ} \times 1^{\circ}$ grid; thus, the impact of peak concentrations is likely to be underestimated. However, given the typical modeled BC lifetime of 6.6 days [Mann et al., 2010], we suggest that this effect will be limited. As the inventories cover the Arctic only, they were merged with the global shipping inventories from Aerosol Comparisons between Observations and Models (AEROCOM) [Dentener et al., 2006] by replacing AEROCOM emissions with $\mathrm{C} 10$ in model grid boxes where $\mathrm{C} 10$ emissions were greater than zero. Where AERO$\mathrm{COM}$ emissions were replaced with $\mathrm{C} 10$, primary aerosol and $\mathrm{SO}_{2}$ emissions increased. The total overlap of the two inventories (grid boxes where $\mathrm{C} 10$ has been substituted for nonzero emissions in AEROCOM) is $40 \%$. Excluding emissions south of $60^{\circ} \mathrm{N}$, this overlap falls to $1 \%$ ( $0.5 \%$ overlap north of $65^{\circ} \mathrm{N}$ ).

[11] Anthropogenic BC emission inventories for nonshipping ( $5 \mathrm{Tg} / \mathrm{yr}$ ) were taken from the AEROCOM hindcast database for 2004 [Dentener et al., 2006]. Wildfire emissions were from the Global Fire Emissions Database (GFED) [van der Werf et al., 2003]. In 2004, wildfires emitted $2.7 \mathrm{Tg} / \mathrm{yr}$ of $\mathrm{BC}\left(0.2 \mathrm{Tg} / \mathrm{yr}\right.$ north of $\left.40^{\circ} \mathrm{N}\right) 0.2 \sigma$ from the 1997 to 2006 mean $\left(0.5 \sigma\right.$ north of $\left.40^{\circ} \mathrm{N}\right)$. Globally, $34 \%$ of BC emissions are attributable to wildfires, $1 \%$ to shipping $(0.01 \%$ to Arctic shipping), and $65 \%$ to other anthropogenic sources. For all other aerosol and gas species, emission inventories were identical to those described in Browse et al. [2012].

\section{Future Emission Scenarios}

\subsection{Business as Usual (BAU)}

[12] The business as usual scenario (BAU) is similar to that described by the Arctic Marine Shipping Assessment (AMSA) [Brigham et al., 2009] as "a healthy rate of Arctic development that includes concern for the preservation of Arctic ecosystems, cultures and shared economic and political interests". In the BAU scenario, the location of shipping lanes changes little between 2004 and 2050, although the density of traffic increases resulting in a factor of 3 increase in $\mathrm{BC}$ emissions.

[13] These emission rates do not include the introduction of controls on BC emissions, which Corbett et al. [2010] suggest could reduce BC emissions by $70 \%$. Thus, the results presented here represent the maximum potential impact of BC shipping emissions projected by Corbett et al. [2010].

\subsection{High Growth Scenario (HiG)}

[14] The diversion or high growth (HiG) inventories are loosely based on the low-regulation Arctic-race scenario described by the AMSA study as "lack of an integrated set of maritime rules and regulations, and insufficient infrastructure to support such a high level of marine activity". Given the uncertainty as to when sufficient sea ice loss will be frequent enough for large-scale diversions to begin, we assume a $5 \%$ diversion of global shipping in 2050 [Corbett et al., 2010].

[15] Legislation concerning shipping fuel standards and sulfate emissions is also included in the $\mathrm{HiG}$ and BAU inventories. Thus, in both BAU and HiG simulations, Arctic annual $\mathrm{SO}_{2}$ emissions decrease between 2004 and 2050 (2500 Mg less than in 2004). A decrease in $\mathrm{SO}_{2}$ emissions could slow the rate of $\mathrm{H}_{2} \mathrm{SO}_{4}$ uptake onto $\mathrm{BC}$ particles, slowing the conversion from insoluble to soluble (cloud active) and increasing the lifetime of $\mathrm{BC}$ aerosol. However, any change in $\mathrm{BC}$ lifetime caused by changes in $\mathrm{SO}_{2}$ is more likely to be controlled by $\mathrm{SO}_{2}$ from natural sources [Gabric et al., 2005; Browse et al., 2013].

[16] As in 2004, both the HiG and BAU inventories were merged with AEROCOM using the method discussed in section 3. North of $60^{\circ} \mathrm{N} \mathrm{HiG} \mathrm{BC}$ emissions in 2050 are a factor of 2 higher than the BAU emissions. Extra-Arctic shipping emissions (those not included in the C10 inventories) were kept the same (for 2004) in all runs. Therefore, this study does not take into account the projected increase in global ship traffic for 2050 [Buhaug et al., 2009]. Likewise, non-shipping $\mathrm{BC}$ emissions remain the same between runs. However, as global $\mathrm{BC}$ emissions are unlikely to remain static over the next 50 years, we examine the impact of low-latitude $\mathrm{BC}$ emission decreases on high-latitude $\mathrm{BC}$ deposition (section 7).

\subsection{Experimental Setup}

[17] To quantify the contribution of shipping emissions to Arctic BC deposition, three core simulations were used:

[18] 1. PD - a present-day run based on 2004 meteorology and a 2000 sea ice climatology, using the merged AEROCOM and C10 shipping inventories discussed in section 3 .

[19] 2. BAU - a run identical to PD but with merged AEROCOM (2004) and BAU shipping inventories from 2050 discussed in section 4.1.

[20] 3. HiG - a run identical to PD but with merged AEROCOM (2004) and HiG shipping inventories from 2050 discussed in section 4.2.

[21] For all simulations, the meteorology (diagnosed from European Centre for Medium-Range Weather Forecasts output) and non-shipping emission inventories were from 2004 and kept identical between the runs. In addition, two sensitivity simulations were performed in which either Arctic or extra-Arctic shipping emissions were set to zero (PD-noAS and PD-no-eAS runs, respectively). Finally, a run for 2004 was completed in which wildfire emissions were set to zero so that the contribution of shipping to anthropogenic high-latitude BC deposition could be quantified.

\section{BC Deposition From Shipping in 2004}

[22] Analysis of deposition rates between PD and PDno-AS shows that Arctic shipping results in $752 \mathrm{Mg} / \mathrm{yr}$ of $\mathrm{BC}$ deposition north of $60^{\circ} \mathrm{N}$ ( $85 \%$ of $\mathrm{C} 10$ emissions), with $80 \mathrm{Mg} / \mathrm{yr}$ and $286 \mathrm{Mg} / \mathrm{yr}$ deposited on sea ice and land surfaces, respectively. The deposited BC mass north of 

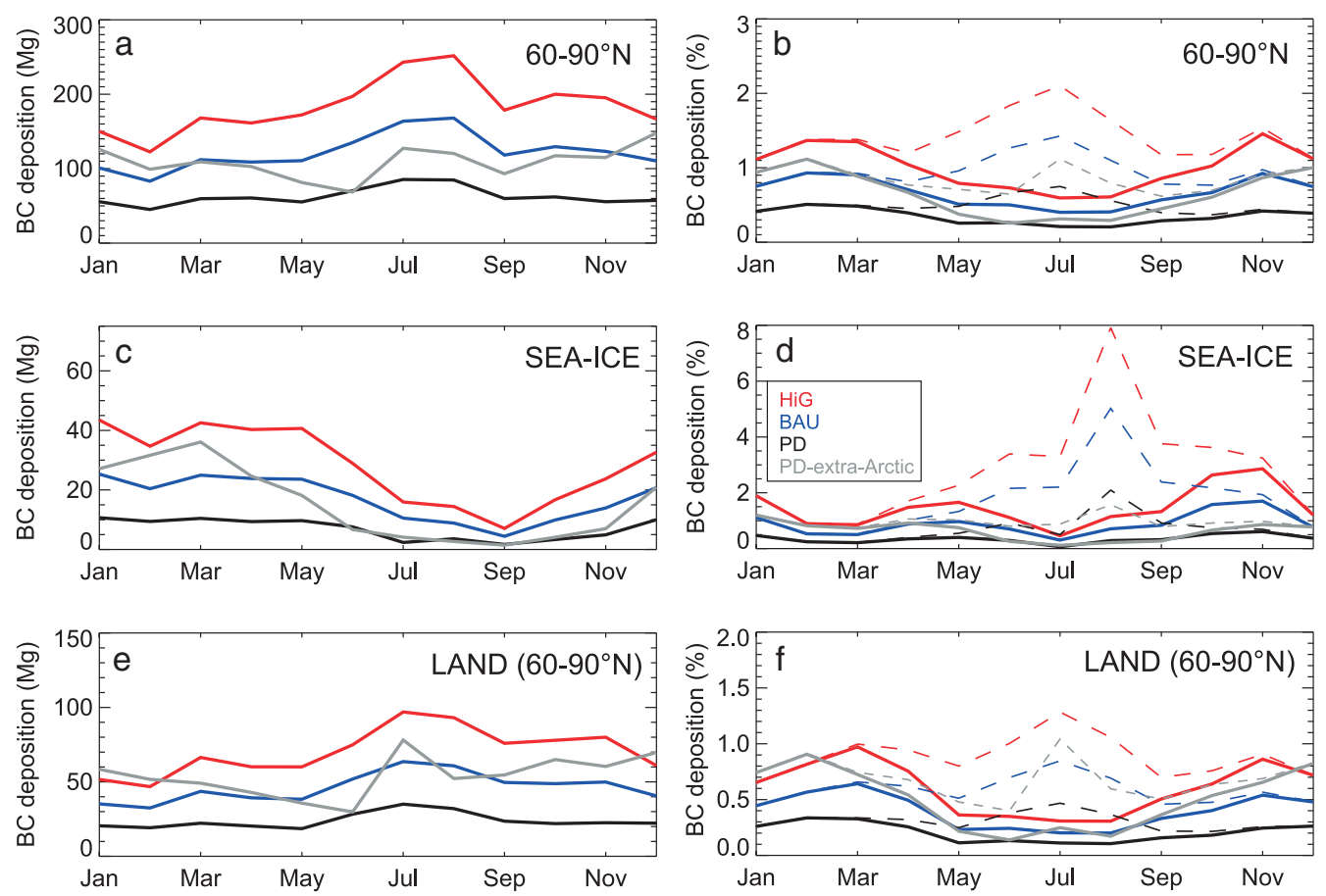

Figure 1. Monthly deposited BC (a, b) north of $60^{\circ} \mathrm{N},(\mathrm{c}, \mathrm{d})$ over sea ice, and (e, f) over land north of $60^{\circ} \mathrm{N}$ attributable to present-day (PD) Arctic shipping in 2004 (black), BAU Arctic shipping in 2050 (blue), HiG Arctic shipping in 2050 (red), and extra-Arctic shipping in 2004 (grey). The percentage (Figures 1b, 1d, and 1f) of deposited BC attributable to shipping sectors is shown relative to the total $\mathrm{BC}$ deposition (solid lines) and the anthropogenic component of deposited $\mathrm{BC}$ (dashed lines).

$60^{\circ} \mathrm{N}$ from Arctic shipping is greatest in July (85 Mg/yr). However, on sea ice, this seasonal cycle is inverted (Figures 1a and 1c).

[23] Annually, Arctic shipping contributes $0.3 \%$ to the BC mass deposited north of $60^{\circ} \mathrm{N}(250 \mathrm{Gg})$. In addition, we estimate that about $50 \%$ of modeled $\mathrm{BC}$ deposition is on open ocean. Our results suggest that reducing current Arctic ship traffic will not significantly decrease BC deposition on central Arctic sea ice (Figure 1d). However, on the west coast of Greenland, $6 \%-8 \%$ of deposited BC originates from local ship traffic (Figure 2).

[24] Extra-Arctic shipping contributes more BC mass to deposition north of $60^{\circ} \mathrm{N}(1300 \mathrm{Mg})$ than Arctic shipping $(752 \mathrm{Mg})$, equivalent to $0.5 \%$ of the total $\mathrm{BC}$ mass.
However, we must consider that $32 \%$ of high-latitude ship sourced $\mathrm{BC}$ deposition $(2000 \mathrm{Mg}$ ) originates from less than $1.0 \%$ of global shipping emissions. Thus, regulation of Arctic shipping could yield a reduction in near-Arctic BC aerosol that leads to a greater decrease in high-latitude $\mathrm{BC}$ deposition than a similar control strategy applied only to the extra-Arctic shipping industry.

[25] Our inventories exclude the contribution of Arctic fishing emissions. Corbett et al. [2010] report that 29\% of emissions in 2004 originate from fishing. Assuming all BC emitted by the fishing industry is deposited locally, BC deposition north of $60^{\circ} \mathrm{N}$ would increase from 752 to $1059 \mathrm{Mg}$ and the contribution of Arctic shipping to high-latitude $\mathrm{BC}$ deposition to $0.4 \%$ ( $0.7 \%$ of anthropogenic $\mathrm{BC}$ deposition).
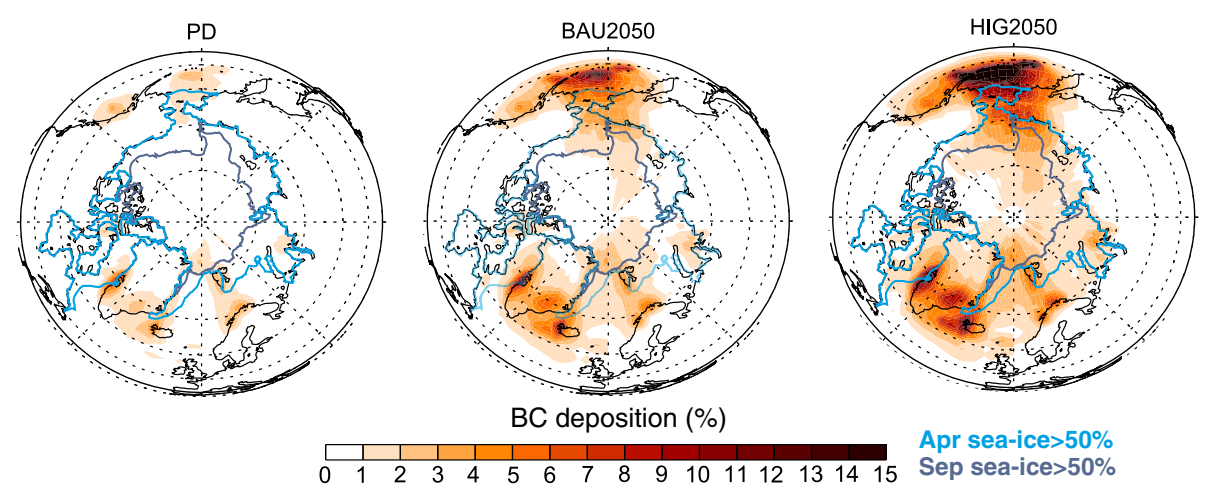

Apr sea-ice $>50 \%$ Sep sea-ice $>50 \%$

Figure 2. Contribution of Arctic shipping emissions to annual BC deposition in 2004 (left) and 2050 for the BAU (middle) and $\mathrm{HiG}$ (right) shipping scenarios. Also shown is the 2000 sea ice edge (sea ice fraction $>50 \%$ ) in April (maximum) and September (minimum). 

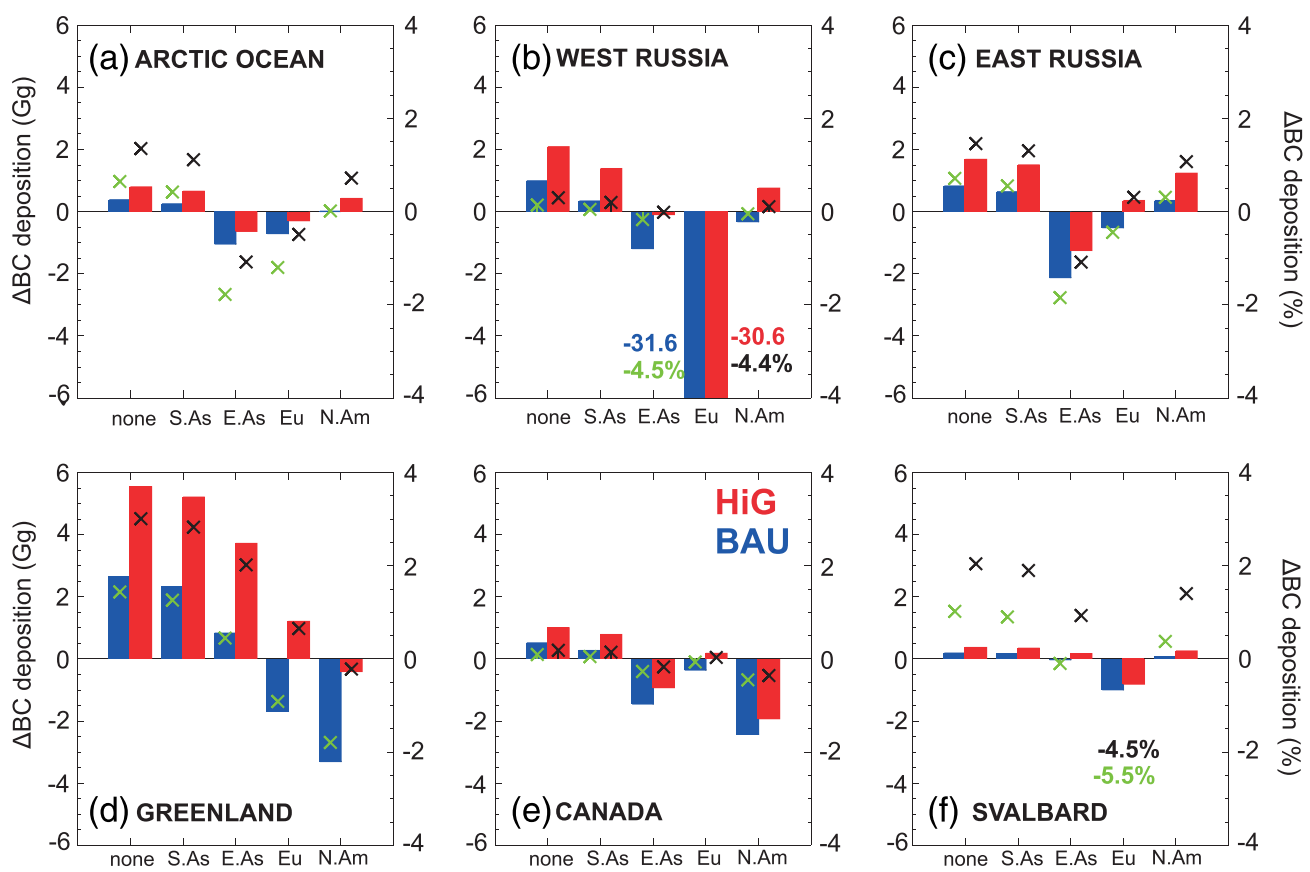

Figure 3. (a-f) Change in annual BC deposition between 2004 and 2050 over six different regions for the BAU (blue) and $\mathrm{HiG}$ (red) shipping scenarios and five different mitigation strategies: no mitigation (none), 10\% reduction in South Asian $\mathrm{BC}$ emissions (S.As), 10\% reduction in East Asian emissions (E. As), 10\% reduction in European emissions (Eu), and 10\% reduction in North American emissions (N.Am). The absolute change (left axis) is shown as the bars while the percentage change (right axis) is shown by the green (BAU) and black (HiG) crosses.

Thus, even when accounting for Arctic fishing emissions, the overall impact of Arctic shipping on high-latitude BC deposition remains low.

[26] Uncertainty in modeled BC deposition has two principal sources. For BC derived from Arctic shipping, the main source of uncertainty is from the emissions themselves [Corbett et al., 2010]. Based on the high-low ratio of estimated emission factors (BC emission per $\mathrm{kWh}$ ) reported by Buhaug et al. [2009] combined with discussion in the literature [Buhaug et al., 2009 and reference therein], we estimate a factor of 3 upper bound on our inventories, increasing Arctic shipping emissions in 2004 to $2640 \mathrm{Mg}$.

[27] For aerosol transported to the Arctic from lower latitudes, the main sources of uncertainty are atmospheric processes that affect long-range transport [Browse et al., 2012; Lee et al., 2012]. The Lee et al. [2012] uncertainty analysis of GLOMAP accounting for 28 parameters and emissions has been extended to $\mathrm{BC}$ (unpublished results). We estimate that Arctic BC concentrations from extra-Arctic sources have a $1 \sigma$ uncertainty between $\pm 70 \%$ in the winter and $\pm 40 \%$ in the summer.

[28] Taking the lower bound estimate for transported BC, the upper bound estimate for shipping emissions (factor of 3) and assuming that this increase in ship emissions affects only the Arctic, we calculate that Arctic shipping contributes a maximum of $1.9 \%$ to annual $\mathrm{BC}$ deposition north of $60^{\circ} \mathrm{N}$ in 2004.

[29] The dominant contribution of $\mathrm{BC}$ aerosol mass from extra-Arctic shipping (and non-shipping) emissions to Arctic $\mathrm{BC}$ deposition is consistent with modeling [Browse et al. 2012] and observational studies [Garrett et al., 2011] and arises from efficient long-range transport processes [Stohl, 2006], low local scavenging rates [Browse et al., 2012], and reduced local emissions [Corbett et al., 2010] during the Arctic winter and spring. Although aerosol is initially transported largely at higher altitudes the surface-level BC is also strongly affected by these processes [Browse et al., 2012], as demonstrated by the strong seasonal cycle in aerosol mass concentrations at Arctic ground sites. Local reductions in ship traffic may have a regional impact, particularly on the West Coast of Greenland (Figure 2). However, to reduce present-day deposition of $\mathrm{BC}$ in the Arctic, extra-Arctic shipping emissions need to be considered alongside Arctic.

\section{BC Deposition From Shipping in $\mathbf{2 0 5 0}$}

[30] The absolute increase in BC deposition north of $60^{\circ} \mathrm{N}$ is consistent with the emission increase from 2004 to 2050 for both the BAU and $\mathrm{HiG}$ scenario, increasing the percentage of Arctic ship emissions deposited north of $60^{\circ} \mathrm{N}$ from $85 \%$ to more than $95 \%$ in 2050 . Overall, the HiG scenario deposits approximately twice as much BC per year north of $60^{\circ} \mathrm{N}$ than the BAU. However, in the BAU and HiG scenarios, the total $\mathrm{BC}$ deposition averaged north of $60^{\circ} \mathrm{N}$ from Arctic shipping remains small, increasing to only $0.4 \%$ and $0.7 \%$, respectively. Using our lower and upper bound estimates for transported BC and Arctic shipping emissions (see above), we project a maximum contribution of Arctic shipping in 2050 to high-latitude $\mathrm{BC}$ deposition of 5\% (assuming no change in extra-Arctic emissions).

[31] Over the west coast of Greenland and the Bering sea, the $\mathrm{BC}$ deposition from shipping emissions rises to $10 \%$ $15 \%$ in the $\mathrm{HiG}$ scenario (Figure 2 ). Thus, future shipping $\mathrm{BC}$ emissions could have a significant impact on the albedo of the sub-Arctic. Our results suggest that the impact of local shipping near the vulnerable Greenland ice sheet may be 
significant. However, as we show below, control of distant sources may be of greater priority to reduce high-latitude $\mathrm{BC}$ deposition.

\section{BC Deposition From Non-Shipping Emissions}

[32] The HiG scenario projected for Arctic shipping emissions results in an increase in $\mathrm{BC}$ deposition north of $60^{\circ} \mathrm{N}$ of $0.5 \%$ ( $0.9 \%$ on sea ice, $0.3 \%$ on land). However, increases of as much as $15 \%$ occur in the sub-Arctic and close to heavy ship traffic (Figure 2). Thus, several mitigation strategies were simulated to (1) confirm that extra-Arctic sources other than shipping contribute significantly more to BC deposition than Arctic shipping and (2) to determine whether $\mathrm{BC}$ deposition from Arctic shipping emissions can be offset by reducing non-shipping emissions at lower latitudes. The model was run with BAU and HiG 2050 shipping emissions in combination with a $10 \%$ decrease in $\mathrm{BC}$ emissions from the industrial regions discussed in the Hemispheric Transport of Air Pollution report (www.htap.org).

[33] Figure 3 shows the change in 2050 BC deposition (assuming BAU and $\mathrm{HiG}$ shipping) over six Arctic regions (discussed in Doherty et al. [2010]) including Greenland. Over Greenland, a 10\% reduction in North American emissions results in a regional reduction in $\mathrm{BC}$ deposition (despite increased ship traffic) (Figure 3d) but does not offset the impact of Arctic shipping on sea ice (Figure 3a) or the eastern continental Arctic (Figures $3 b$ and 3c). However, this solution assumes implicit equalization of these mitigation options, which is an unlikely scenario.

\section{Conclusions}

[34] We used a global model of aerosol processes (GLOMAP) combined with new shipping inventories for 2050 [Corbett et al., 2010] to quantify the relative contribution of Arctic shipping emissions to high-latitude $\mathrm{BC}$ deposition in 2004 and 2050. BC emissions from shipping were found to contribute $0.3 \%$ to the total $\mathrm{BC}$ mass deposited north of $60^{\circ} \mathrm{N}(0.5 \%$ of the anthropogenic BC mass) in 2004 and $0.7 \%$ (1.4\% of the anthropogenic) in a 2050 high growth scenario (Figure 1). However, regional impacts were found to be higher.

[35] Over Greenland, the deposited BC mass attributable to high growth shipping emissions in 2050 is $10 \%-15 \%$ (Figure 2). This increase in regional BC deposition can be mitigated by a $10 \%$ decrease in North American BC emissions (Figure 3d). However, reductions in one lone region are insufficient to reduce $\mathrm{BC}$ deposition over the entire Arctic (Figure 3).

[36] Our results imply that future shipping emission increases are sufficiently small that over the entire Arctic, they are unlikely to be measurable against natural emission variability from wildfires, changes in transport efficiency, or reductions in lower latitude anthropogenic emissions, which will also reduce the remote Arctic forcing resulting from midlatitude $\mathrm{BC}$ aerosol concentrations [Sand et al., 2013; Flanner, 2013]. Thus, to achieve desired Arctic BC deposition reductions, controls over distant stationary sources, which may be more likely due to existing air quality standards, should be considered alongside international agreements controlling shipping emissions.
[37] Acknowledgments. J.B. was funded by a studentship from the Natural Environment Research Council (NERC) and by the Met Office through a CASE partnership and is now funded by a NERC grant [NE/I028858/1]. K.C. is a Royal Society Wolfson Merit Award holder. A.S. is funded by a NERC grant [NE/I015612/1] and a fellowship from the School of Earth and Environment, University of Leeds.

[38] The Editor thanks three anonymous reviewers for their assistance in evaluating this paper.

\section{References}

Buhaug, Ø., et al., (2009), Second IMO Greenhouse Gas Study, Tech. rep. International maritime organization, London.

Brigham, L., et al., (2009), Arctic Marine Shipping Assessment 2009 report, Tech. rep., Arctic Council, Tromsa, Norway.

Browse, J., K. S. Carslaw, S. R. Arnold, K. Pringle, and O. Boucher (2012), The scavenging processes controlling the seasonal cycle in Arctic sulphate and black carbon aerosol, Atmos. Chem. Phys., 12, 6775-6798.

Browse, J., K. S. Carslaw, G. W. Mann, C. E. Birch, S. R. Arnold, and C. Leck (2013), The complex response of Arctic cloud condensation nuclei to sea-ice retreat, Atmos. Chem. Phys. Discuss., 13, 17,087-17,121.

Breider, T. J., M. P. Chipperfield, N. A. D. Richards, K. S. Carslaw, G. W. Mann, and D. V. Spracklen (2010), Impact of BrO on dimethylsulfide in the remote marine boundary layer, Geophys. Res. Lett., 37, L02807, doi: $10.1029 / 2009$ GL040868.

Corbett, J., D. Lack, J. Winebrake, S. Harder, J. Silberman, and M. Gold (2010), Arctic shipping emissions inventories and future scenarios, Atmos. Chem. Phys, 10, 9689-9704.

Dalsøren, S. B., Ø. Endresen, I. S. A. Isaken, G. Gravir, and E. Sørgård (2007), Environmental impacts of the expected increase in sea transportation, with a particular focus on oil and gas scenarios for Norway and northwest Russia, J. Geophys. Res., 112, D02310, doi:10.1029/2005JD006927.

Dentener, F., et al. (2006), Emissions of primary aerosol and precursor gases in the years 2000 and 1750 prescribed data-sets for AeroCom, Atmos. Chem. Phys., 6, 4321-4344.

Doherty, S. J., S. G. Warren, T. C. Grenfell, A. D. Clarke, and R. E. Brandt (2010), Light-absorbing impurities in Arctic snow, Atmos. Chem. Phys., 10, 11,647-11,680.

Flanner, M. G. (2013), Arctic climate sensitivity to local black carbon, $J$. Geophys. Res. Atmos., 118, 1840-1851, doi:10.1002/jgrd.50176.

Gabric, A. J., B. Qu, P. Matrai, and A. C. Hirst (2005), The simulated response of dimethylsulphide production in the Arctic Ocean to global warming, Tellus B, 57, 391-403.

Garrett, T., S. Brattström, S. Sharma, D. E. J. Worthy, and P. Novelli (2011), The role of scavenging in the seasonal transport of black carbon and sulfate to the Arctic, Geophys. Res. Lett., 38, L16805, doi:10.1029/2011GL048221.

Lack, D. A., B. Lerner, C. Granier, T. Baynard, E. Lovejoy, P. Massoli, A. R. Ravishankara, and E. Williams (2008), Light absorbing carbon emissions from commercial shipping, Geophys. Res. Lett., 35, L13815, doi:10.1029/2008GL033906.

Lack, D. A., et al. (2009), Particulate emissions from commercial shipping: Chemical, physical, and optical properties, J. Geophys. Res., 114, D00F04 doi:10.1029/2008JD011300.

Lee, L. A., K. S. Carslaw, K. J. Pringle, and G. W. Mann (2012), Mapping the uncertainty in global CCN using emulation, Atmos. Chem. Phys., 12, 9739-9751.

Mann, G. W., et al. (2010), Description and evaluation of GLOMAP-mode: A modal global aerosol microphysics model for the UKCA compositionclimate model, Geosci. Model Dev., 3, 519-551, doi:10.5194/gmd3-519-2010

Ødemark, K., S. Dalsøren, B. Samset, T. Berntsen, J. Fuglestvedt, and G. Myhre (2012), Short-lived climate forcers from current shipping and petroleum activities in the Arctic, Atmos. Chem. Phys., 12, 1979-1993.

Sand, M., T. K. Berntsen, J. E. Kay, J. F. Lamarque, Ø. Seland, and A. Kirkevåg (2013), The Arctic response to remote and local forcing of black carbon, Atmos. Chem. Phys., 13, 211-224.

Stier, P., et al. (2005), The aerosol-climate model ECHAM5-HAM, Atmos. Chem. Phys., 5, 1125-1156.

Stohl, A. (2006), Characteristics of atmospheric transport into the Arctic troposphere, J. Geophys. Res., 111, D11306, doi:10.1029/2005JD006888.

Skeie, R. B., T. Bernsten, G. Myhre, C. A. Pedersen, J. Ström, S. Gerland, and J. A. Ogren (2011), Black carbon in the atmosphere and snow, from pre-industrial times until present, Atmos. Chem. Phys, 11, 6809-6836.

van der Werf, G. R., J. T. Randerson, G. J. Collatz, and L. Giglio (2003), Carbon emissions from fires in tropical and subtropical ecosystems, Glob. Change Biol., 9, 547-562. 